\title{
AC 2007-935: ENGINEERING EDUCATION: THE UK CHALLENGE
}

\section{Ian Robinson, Edge Hill University}

Professor Ian Robinson is the Dean of Quality Enhancement at Edge Hill University and was previously Professor of Engineering Education at Sheffield Hallam University. Technically he specialised in electrical drives and power electronics, but now spends much of his time working in the area of engineering pedagogy and academic quality. He is a member of the International Liaison Group for Engineering Education and is a member of the editorial board of Engineering Education, the Journal of the Higher Education Academy Engineering Subject Centre.

\section{Michael Bramhall, Sheffield Hallam University}

Mike is Head of Learning, Teaching and Assessment at Sheffield Hallam University's Faculty of Arts, Computing, Engineering and Sciences. He is the Associate Director of the Centre for Promoting Learner Autonomy at Sheffield Hallam. He is also the Associate Director of the UK Centre for Materials Education at Liverpool University, which is part of the UK Higher Education Academy.

\section{John Rowe, Sheffield Hallam University}

Dr Rowe is a member of the teaching staff in the Faculty of Arts, Computing, Engineering and Sciences at Sheffield Hallam University. He has taught for 21 years in microelectronics and IT in higher education. His current areas of research are in the search for quality in higher education, research methodologies and teaching and learning in technical education. 


\title{
ENGINEERING: THE UK CHALLENGE
}

\begin{abstract}
This paper reviews experiences of the development of teamwork and leadership skills, personal reflection, planning and other transferable skills within engineering bachelors degrees within the UK over the last 15 years, illustrated by examples from one particular University. It provides a picture of the current state of UK engineering education, and reflects upon strengths and weaknesses. Comparisons are drawn with both European and North American provision and includes a view of the possible future for British Engineering Education.
\end{abstract}

\section{Introduction}

Within the UK, there are three principal drivers and influencers for Bachelors programmes of Higher Education (HE):

- The employment market for graduates

- The funding available to provide degree level education

- Professional and Statutory Regulatory Body (PSRB) and Government requirements

\section{The employment market}

With a few exceptions (typically where the national Government wishes to control the supply of graduates, for example teachers, doctors, nurses), UK universities are free to design degree courses and to offer them to potential students. Clearly the most successful courses will attract applications if they are able to offer a strong likelihood of employment upon graduation. It is thus crucially important for universities to be aware of the employment market, and over the past several decades most universities have only developed new provision in vocational subjects. Non-vocational areas have very little attraction to students, and the volume of such provision has declined significantly.

\section{The funding regime}

The British Government provides each English University with approximately $50 \%$ of the funding necessary to educate a Bachelors student. Universities charge additional annual fees of between $£ 1200$ and $£ 3000$, the permitted fee range being regulated by central Government. It is only relatively recently that Universities were required to charge students directly for their tuition. A mandatory $£ 1200$ fee was introduced in the mid 1990s, and the extension of the fee limit to $£ 3000$ pa was introduced in 2005 . The total fee accruing from an engineering Bachelors student is insufficient to pay the actual cost of delivering laboratory-based education, and so universities rely upon distributing the surplus fees from other discipline areas and other business activities to support science and technology provision.

The majority of students secure loans from the English Student Loan Company in order to pay their fees; the debt being collected through the taxation system over the graduate's working life. 
It has thus, in the last few years, become increasingly important to English students that firstly they are able to obtain employment upon graduation, and secondly that their university education makes a positive contribution to salary prospects.

\section{Professional and statutory body requirements}

Where courses lead to recognition and accreditation by PSRBs, then it is crucial that course designers acknowledge the requirements of professional bodies in their course design. For engineering in the UK, the Engineering Council (EC) articulates the general requirements in UK-SPEC $^{1}$. Further detailed regulations may be published by each professional body; for example, the Institution of Mechanical Engineers publishes its requirements in The Educational Base $^{2}$. Courses which are submitted for accreditation are subject to detailed scrutiny, both by consideration of a written submission, and by a visit from an accreditation panel which observes resources, and meet students and teaching staff. As with the ABET process, UK Engineering PSRB accreditation is a robust procedure and provides intending students (and their sponsors) with significant quality assurance.

\section{The impact of employers upon engineering degree courses}

Both the requirement to find employment upon graduation, and the requirements of employers have had a major impact upon the engineering curriculum. This impact has been studied in some detail by Robinson, Bramhall and Harris ${ }^{3}$, and is summarised below.

The changing nature of both engineering business and higher education persuaded the government of the day to commission Sir Monty Finniston to conduct a major review in 1980 regarding the need for engineers; the type of engineering expertise the country required; and the framework for the formation of engineers (The Finniston Report ${ }^{4}$ ). This report found that professional engineers:

'...expect to find themselves taking part in, and responding to a more participative process of change, through joint discussions of their work and its impact and effects at many levels. This wider role will require that engineers develop appropriate skills in the following areas:

- the ability to express and communicate both verbally and in writing

- managing and participating in meetings

- mastery of cost and budget information'

'the ability to give authoritative advice on innovation and change, to manage the development and implementation of new technologies, coupled with the ability to appreciate and take cost/ benefit account of the financial, social and political implications of decisions taken' ${ }^{1}$.

In short, engineering graduates were required to be business-minded for the first time.

By 1988, the Engineering Council was becoming more outspoken, observing that 'education for working life rather than first job should...be the aim'. The engineer in industry must be 'an authority on technology, a leader of others, a communicator' and engineering courses must 'improve working habits' 5 . The council was itself beginning to warm to the theme of intervention in the undergraduate curriculum, and would indeed be funding and influencing new engineering degree courses using the UK Government's Department of Trade and 
Industry (DTI) finance. The links to industry and the world of work were clearly being reenforced.

However, it was not only industry, as the end user, who had demonstrated an interest in these wider professional skills. Students themselves were beginning to perceive the importance of studying on a course which explicitly encouraged the development of knowledge and skills firmly rooted in the business-oriented context of the modern engineering industry. In his 1992-3 Presidential Address, the President of the Institution of Electrical Engineers reviewed the trends within engineering education, and drew attention to "the search by students for courses which provide them with wider skills, ${ }^{3}$.

The Engineering Council, in SARTOR ${ }^{7}$, an earlier version of UK-SPEC, continued the increasingly strong trend of basing the curriculum within the vocational arena, and argued that engineering courses must give 'greater breadth and depth of coverage, to meet the needs of industry in management and business topics and personal skills'. In fact, the tone of this document marked a significant change in the level of control governmental bodies were beginning to exercise over the HE institutions. There were very specific guidelines about exactly what a course should include. Such as:

'...an awareness of quality systems in engineering; requirements and responsibilities of leadership; obligations to work safely and to apply safe systems of work; risk analysis; the financial, economic, social and environmental factors of significance to engineering; the relevant legal, statutory and contractual obligations and the broader obligations of engineers in society' 7 .

\section{The impact of the professional and governmental bodies - personal skill development}

The professional bodies acknowledged the need for the development of professional skills in the engineering undergraduate curriculum, and had stated the requirement clearly within SARTOR. This was routinely tested during accreditation visits throughout the 1990s. Universities adopted a variety of methods for embedding skill development within the curriculum, typically within case study modules, within the assessment of final year projects, and within modules designed to specifically to encourage practical engineering applications throughout the three years of study.

The Engineering Council wished to proactively encourage more radical curriculum development, and working with other bodies launched national initiatives to embed design within the engineering curriculum, and to develop a more general, skills focussed engineering course. Sheffield Hallam University was one of the early institutions which launched such an 'Integrated Engineering Degree Programme' (IEDP) ${ }^{8}$. The programme, and others similar elsewhere in the UK, received wide acclaim, and shifted the balance of the curriculum from the assessment of knowledge to the development and evaluation of students' abilities to apply knowledge within an engineering environment. Assessment was predominantly by a portfolio of work rather than by unseen examination, in itself a significant change from normal methods of measuring student achievement in engineering courses.

The development of portfolio assessment of project and case study work required reflective skills of the students. In addition, they would need to be able to plan their own personal future development, and influence their own learning opportunities. Most Bachelors students were not prepared for such responsibilities, and at Sheffield Hallam it was found necessary to 
build in Professional and Personal Development mechanisms to support students in such work. The introduction of such support improved student retention so significantly that the support was rolled out on all engineering undergraduate courses at Sheffield Hallam, and the concept was grasped by the engineering professional bodies, and introduced as a requirement for accreditation by the Engineering Council. Similar lessons were concurrently learned in other discipline areas, and the provision of opportunities for students to engage in Personal Development Planning (PDP) is now a Government requirement for all UK university degrees.

Teamwork and Leadership skills were also developed within the IEDP. Engineering undergraduates were taken on a residential weekend course to undertake skills training and engage in personal reflection on their abilities to lead and work in teams. The course has been so successful that it has now been extended to all students in the professional engineering undergraduate programme, and is oversubscribed!

The use of project- and problem-based learning within the curriculum was not broadly welcomed within the engineering community. Whilst the IEDP itself was welcomed by the professional bodies, who accredited such courses with relative ease, university staff found the student support and assessment regime challenging; it was time-intensive, and took focus away from personal research activity. However, in a few cases, it was adopted; several universities extended the approach more broadly, and have launched entire programmes based around problem-based learning ${ }^{9}$.

Portfolio assessment is tutor-intensive, and after some 12 years of operation, in the face of diminishing Government funding for technical degree courses, the IEDP closed at Sheffield Hallam, although leaving a truly positive legacy in terms of PDP and associated student support mechanisms.

In the USA, $\mathrm{ABET}^{10}$, in moving to an outcomes base, now requires engineering programmes to demonstrate that students, amongst other technical skills, attain:

- an ability to design and conduct experiments, as well as to analyze and interpret data

- an ability to engage in engineering design to meet desired needs within realistic constraints such as economic, environmental, social, political, ethical, health and safety, manufacturability, and sustainability

- an ability to function on multi-disciplinary teams

- an ability to identify, formulate, and solve engineering problems

- an understanding of professional and ethical responsibility

- an ability to communicate effectively

- the broad education necessary to understand the impact of engineering solutions in a global, economic, environmental, and societal context

- a recognition of the need for, and an ability to engage in life-long learning

- a knowledge of contemporary issues

- an ability to use the techniques, skills, and modern engineering tools necessary for engineering practice.

The Sheffield Hallam Portfolio assessment model on the IEDP measured all of these criteria within a student's portfolio a number of years before the publication of these ABET requirements. 


\section{The impact of the professional and governmental bodies - curriculum guidance}

The Finniston Report ${ }^{4}$, led to the engineering professional bodies issuing strong guidance to university departments seeking professional accreditation for their courses. The EC's $\mathrm{SARTOR}^{7}$ set general expectations (for example regarding the centrality of design within the curriculum, the need for professional skill development, the requirement to expose students to a range of practical engineering processes through Engineering Applications), and the individual specialist institutions gave specific curriculum advice. This advice was typically very broad, listing the subjects to be included, but without giving any detail; individual universities had significant control over the detailed curriculum development.

By the late 1990s the UK Quality Assurance Agency (QAA), the national body charged with the regulation of the quality of higher education, had established a strong framework for the Academic Infrastructure. The infrastructure clearly delineated between Bachelors and Masters provision, a distinction that had previously been somewhat blurred. In order to give clear guidance to Universities, the QAA published a series of Subject Benchmark Statements ${ }^{11}$ which detailed a series of knowledge and competencies expected of engineering graduates. The Benchmark acknowledged that the increasing pressure to embrace the need for a general business and commercial foundation, yet at the same time include the core engineering subject curriculum, meant that the typical three year Bachelors degree provided insufficient study time. Consequently, both this national benchmark, and the latest version of SARTOR recognised the preferred educational base for registration as a professional engineer to be the completion of a four year Master of Engineering degree course. In such courses, an integrated programme embraced both a standard Bachelors curriculum, together with a further year of post-graduate study. The national guidance also significantly reduced the emphasis upon student professional and personal skills. Under national direction, the curriculum initiatives of some 13 years had, at a stroke, been reversed.

Sheffield Hallam was one of the first institutions to offer the MEng degree in the UK, and whilst typically less that $25 \%$ of engineering students enrol upon such programmes, it remains a central feature of Sheffield Hallam's provision ${ }^{12}$. Sheffield Hallam's particular MEng programmes have retained the focus upon professional skill development, despite the direction offered by the national guidelines.

\section{The longer-term challenges for engineering education}

Whilst the professional focus upon skill development has largely disappeared from the engineering curriculum, the national funding body has mitigated against the negative impact. Generous funding has been made available to Universities to establish centres of pedagogic excellence (Centres of Excellence in Teaching and Learning or CETLs). Many Universities have bid for, and received, awards to establish CETLs, and whilst the mission of each CETL is unique, many include employability and skill development within their remit. At Sheffield Hallam, the CETL initiatives are concerned with both student employability and the development of students as autonomous learners. Engineering students, as well as many others in the University are thus able to benefit from funded curriculum enhancement and student support.

The introduction of direct entry to four year Masters programmes has understandably raised entry qualifications of undergraduate degree programmes. There is naturally some concern that the introduction of minimum entry requirements above those for the rest of HE will lead 
to a reduction in the number of departments able to offer accredited degree programmes for Chartered and Incorporated Engineer. We predict closures of many excellent departments. Engineering is an expensive discipline to maintain in the University environment, and a number of departments thus feel under threat. There is already a discernible trend towards the development of new degree programmes that may lead to registration at a lower level on the professional engineering register. In many cases, these are BSc programmes rather than BEng, and perhaps ally themselves more closely with the Engineering Technology degrees of North America rather than the more analytical Engineering degrees. They are generally focused on an 'attractive' specialisation (eg Computer and Network Engineering).

Some predict that market forces will prevail, and the longer term outcome will be an enhancement of the status of the professional engineer, and a commensurate increase in the salaries that such staff can command.

The reduced emphasis upon Personal and Professional skills within the engineering sector leads us to predict the introduction of compulsory Continuing Professional Development (CPD) in order to maintain registration as a professional engineer. Lifelong Learning as a concept in UK education is likely to be strongly reinforced.

Meanwhile, other curriculum initiatives are gaining momentum. The CDIO (Conceiving Designing - Implementing - Operating) initiative, launched in $S_{w e d e n}{ }^{13}$ aims to improve undergraduate engineering education in Sweden, the USA and worldwide. The goals are to educate students to:

- Master a deep working knowledge of technical fundamentals

- Lead in the creation and operation of new products and systems.

- Understand the importance and strategic value of their future research work.

In providing students with an education that stresses engineering fundamentals set in the context of real-world systems and products, it has four themes:

- Curriculum reform to ensure that students have opportunities to develop the knowledge, skills and attitudes to conceive and design complex systems and products.

- Improved level of teaching and learning necessary for deep understanding of technical information and skills.

- Experiential learning environments provided by laboratories and workshops.

- Effective assessment methods to determine quality and improve the learning process.

Whilst the aims of this rapidly spreading approach to Engineering education are laudable, they do lack the emphasis upon personal skill development that has driven much of the curriculum reform of the last two decades. Perhaps skill development in the engineering curriculum has had its time?

\section{Does the UK lead, or are we on our own?}

In Germany, East Europe and the Nordic countries the Humboldtian tradition regarding the purpose of the university and specifically research, guides engineering education. Within this idea of a university, institutions are strongly encouraged to contribute autonomous research independent of political and industrial forces. As a result engineering education in those countries tended to be longer (typically 7 or 8 years) and the graduating engineers should be 
sufficiently skilled to take part in research. Clearly, education of this type is very expensive and programmes in Germany are becoming shorter. The industrial requirement for engineers is partly met by the Fachhochsculen 3 year engineering courses although these courses are academically below the equivalent UK courses for practical/industrial engineers.

In the French tradition the engineer is at, or near, the top of the social/professional hierarchy and is more related to a manager than a technician. The French engineer is expected to find a comprehensive answer to specific social or human needs. French engineering education involves, at its elite level, highly competitive entry to the Grandes Ecoles with courses lasting 5 to 6 years. From a strong theoretical standpoint, the French curriculum emphasises general and multidisciplinary engineering education, supported by careful methodological development. Unlike the German tradition, the French engineer is less oriented towards research. Mirroring the German Fachochschulen in the French system a range of less prestigious and shorter programmes of study are available again at the equivalent to the UK sub-bachelors level. In other European countries, other distinctive systems of engineering education exist ${ }^{14}$.

\section{A conclusion}

Our analysis shows that in the UK, engineering students have access to Government support (in the form of loans) throughout their degree study. UK students typically receive funding for three years. Engineers are able to study for four years, on professionally regulated and accredited courses, and almost uniquely are financially supported in their study at masters level. Co-incidentally, other national initiatives have provided additional support for the development of professional skills.

Within the rest of Europe, developments largely fall into two categories. Those countries whose education follow the style of the French Higher Education system have changed little. Professional engineering degree programmes are amongst the elite. Students study for five years, and are assured extremely good employment prospects. The curriculum is academic, heavily analytical, and with very little professional skill development. Engineering is perceived as an excellent training for work in the public and service sectors, and many move out of engineering into public service.

In both Germany and the erstwhile Eastern Europe, financial pressures have generally reduced the length of degree programmes (European spending on HE was on average $1.2 \%$ of GDP compared with $2.7 \%$ in the US during $2003^{15}$ ). These countries have typically reduced programmes from five to three (Bachelors) and four (Masters) years. The Western nomenclature of BSc and MSc has largely replaced the Diploma. This process has been aided by the Bologna agreement ${ }^{16}$ which embeds transferability amongst signatories but does not promote convergence of the system of HE.

So, we argue that, almost by accident, the UK Engineering Education system leads the rest of Europe. In the French system, few students progress to practice as engineers. Elsewhere, systems are evolving rapidly towards that of the UK, but without the sophistication of the employability agenda existing in the UK.

When compared to Engineering Education in North America, the UK national guidelines ensure a more consistent approach to curriculum development, producing highly employable engineers. Students pay significantly less for their University education, and given the 
constrained fee range, students will generally make choice based upon curriculum options rather than financial considerations.

We therefore surmise that whilst curriculum may be similar in North America and elsewhere in Europe, UK engineering students at present either receive a more attractive financial package, or receive funding directly to Masters level. The UK perhaps leads by a short head!

\section{Bibliography:}

1. The Engineering Council, The UK Standard for Engineering Professional Competence (UK-SPEC) (2004)

2. Institution of mechanical Engineers, Educational Base and Criteria for Degree Accreditation, at http://www.imeche.org.uk/membership/profdev_link.asp, accessed on 5 March 2007.

3. Robinson, .I M., Bramhall, M. D. \& Harris, R. G., Personal, professional and transferable skills in engineering education, Global Congress on Engineering Education, Cracow, Poland (1998).

4. Finniston, M., Engineering Our Future; Report of the Committee of Inquiry into the Engineering Profession, London, HMSO, Cmnd 7794 (1980).

5. Engineering Council, An Integrated Engineering Degree Programme-Consultative Document, London, Engineering Council (1988).

6. Manley, B. W., Learning our lessons: The future of education and training in Britain. Engineering Science and Education Journal, Vol 1 No 1, pp3-18 (1992).

7. Engineering Council, Standards and Routes to Registration, London, Engineering Council (1997).

8. Engineering Council, An Integrated Engineering Degree Programme-Consultative Document, London, Engineering Council, 4 (1988).

9. http://www.pble.ac.uk, accessed on 16 January 2007.

10. http://www.abet.org/forms.shtml accessed on 5 March 2007.

11. http://www.qaa.ac.uk/academicinfrastructure/default.asp accessed on 5 March 2007.

12. Robinson, I.M., Bramhall, M.D., Lawson, J.S., Business and Management in the Engineering Curriculum, Proceedings of the American Society for Engineering Education Annual Conference \& Exposition, Chicago, (2006).

13. Berggren, K. F., Brodeur, D., Crawley, E.F., Ingemarsson, I., Litant, W.T.G., Malmqvist, J., Östlund, S., CDIO: An international initiative for reforming engineering education, UICEE, World Transactions on Engineering and Technology Education, Vol.2, No.1 (2003).

14. Giot, M. \& Grosjean, P.D, Higher Engineering Education in Europe, (1995), synopsis available at http://www.bath.ac.uk/ewl/ewleurop.htm accessed 6 March 2007.

15. OECD, Education at a Glance. Paris: OECD, 2003, 2004, 2005.

16. European Council, The European Higher Educatin Area - The Bologna Declaration, (1999) available online at http://www.coe.int/T/DG4/HigherEducation/EHEA2010/BolognaPedestrians_en.asp accessed 16 January 2007. 